\title{
Geodiagnostics of lithogydrogenic systems for forecasting exoggeodynamic processes
}

\author{
Anatoliy Yamashkin ${ }^{1}$, Stanislav Yamashkin ${ }^{1, *}$, Vladimir Erofeev ${ }^{1}$, and Anna Piksaykina ${ }^{1}$ \\ ${ }^{1}$ National Research Mordovia State University, Saransk, Republic of Mordovia, 430005, Russia
}

\begin{abstract}
The landscape indication, based on the automated analysis of remote sensing data, is one of the key methods of research and mapping of lithohydrogene geosystems. The article describes a set of methods for effective detection of types of lithohydrogene systems, including a set of modules for identifying dynamic and invariant descriptors of the territory; assessment of geophysical diversity of landscapes; analysis of the geophysical shell through the calculation of the descriptors of the neighborhood; ensemble-analysis of remote sensing data for monitoring the state of geosystems and forecasting of natural processes. The system of methods for detecting types of landscapes made it possible to conduct geodiagnostics of lithohydrogene systems of the Privolzhskaya Upland and the marginal part of the Oka-Don lowland reservoir within the boundaries of the Republic of Mordovia in order to predict the development of exogeodynamic processes.
\end{abstract}

\section{Introduction}

The most important directions of modern research in the Earth sciences are the development of a methodology and methods for searching for patterns of development of exogeodynamic processes (EGP) for forecasting development and minimizing (warning) manifestations of natural and man-made emergency situations. GIS-technologies are used as the basic tool of research of the space-time organization of geosystems. The information space created with the help of regional GIS optimizes the organization of ecological monitoring over the state of lithohydrogene geosystems - multicomponent formations of geological environment - rocks and tectonic structures that determine hydrogeodynamics and hydrogeochemistry of groundwater, regional and local balance of matter and energy, development of exogeodynamic processes (karst, landslide formation, suffusion, thermodynamics, etc.). The separated lithohydrogene geosystems have a definite vertical structure of geogrhorizons - a combination of natural components whose composition and radial connections determine the genesis, structure, development, dynamics and functioning of landscapes. As the leading method for their study and mapping, a landscape indication based on the use of multizone space is used.

\footnotetext{
*Corresponding author: yamashkinsa@mail.ru
} 


\section{Initial materials and methods of automated geodiagnostics}

The regional geographic information system "Mordovia" was used as the main sources of information on the regularities in the development of EGP, including, in addition to electronic topographic maps of the space imagery, more than 150 thematic maps and databases [1]. To analyze the development of EGP, morphometric and morphological information was used on the manifestations of landslide, erosion, suffosion, karst processes. Each manifestation of the process in the attributive table was assigned characteristics (width, length, depth, exposure, absolute marks, etc.), as well as databases on groundwater discharge-sources, springs, moches, marshes, lakes, etc.

As a testing ground for the development of the geodiagnostics of the EGP, the northwestern slopes of the Privolzhskaya Upland and the marginal part of the Oka-Don lowland, within the boundaries of the Republic of Mordovia (figure 1), were considered.

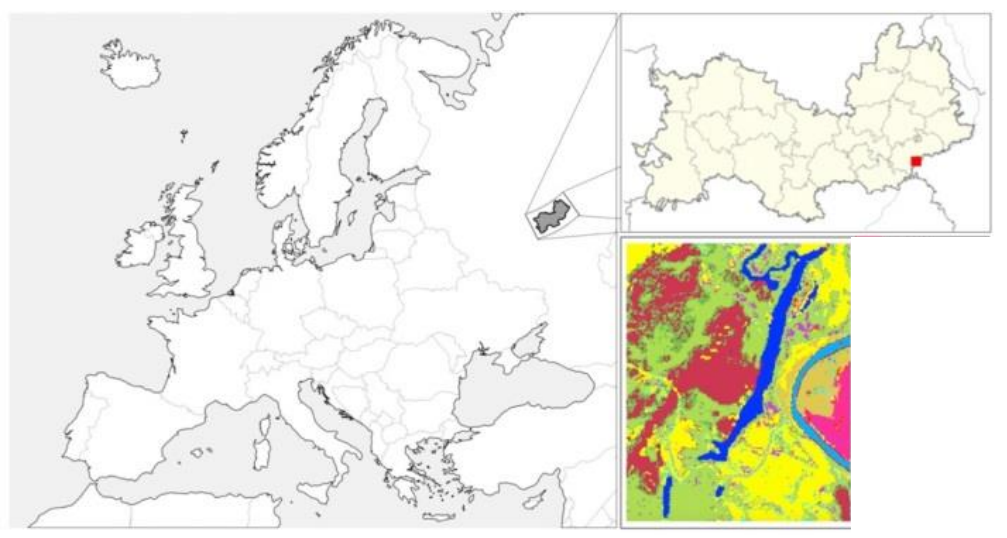

Fig. 1. Geography location of research region.

The construction of a synthetic map of lithohydrogene geosystems was based on the interpretation of multi-zonal space images, in the process of which information resources of thematic maps of the regional GIS "Mordovia" were taken into account [2]: features of the structure of the lithogenic basis of landscapes - bedrock rocks, tectonics, Quaternary sediments, relief, depth of groundwater, from the surface of aquifers; genetic types, subtypes, genera and soil types, with the characteristics of the mechanical composition of soils; restored vegetation cover; Features of economic development and use.

The medium-scale synthetic geoecological mapping of lithohydrogene geosystems uses a hierarchical system of taxa:

- classes and subclasses of geosystems, reflecting features of morphotectonics - tectonic forms of relief, differing in age and dynamics of development; modified by weathering, erosion and accumulation processes; in the subclass of the elevated landscapes of the Volga Upland, a high-altitude change of landscapes is shown: meadow-steppe, forest-steppe, forest;

- groups and subgroups of geosystems, reflecting the combination of the two main migration geochemical streams; vertically directed radial, carrying out the exchange of matter between tiers of the geochemical landscape, and lateral - slope and intrasoil flows in conjugate systems; type of water and water-geochemical regime;

- types and subtypes of geosystems, distinguished by the features of the development of soil-biological processes, determining the formation of types and subtypes of soils, classes of plant formations; this level of landscape differentiation is expressed in the manifestation in different types of lithogenic basis of zonality, intrazonality, extrazonality; 
- genera and subgenus of geosystems, distinguished by the morphology and genesis of the relief, the lithological composition of the surface sediments; morphosculptural forms of the earth's surface and their constituent deposits representing the result of the activity of exo-geodynamic processes (types of erosion relief, karst forms, etc.); differences in the lithogenic basis determine the formation of micro- and mesoclimatic conditions, the features of the water and geochemical regime, the structure of soil combinations;

- types of geosystems - the place of growth and the community of plants.

Instrumental interpretation of remote sensing (RS) data is based on methods and algorithms for analyzing data signals [3-5], statistical classification [6], neural networks [7], support vector machines [8] and ensembles [9]. To improve the effectiveness of detecting the types of territories, a set of methods has been developed. Each of them is informative in distinguishing certain characteristic direct or indirect features of the studied area, but in combination they are capable of giving the most effective and accurate result of a landscape indication. The following is a list of methods that make up the system of effective geodiagnostics:

1) The block of allocation of dynamic and invariant descriptors of the territory operates on the assumption that in order to form an informative spatio-temporal characteristic of the geophysical shell, it is expedient to rely on a system analysis of data that describes the dynamic and invariant states of the vicinity of the geophysical site. This is due to the fact that the analysis of the neighborhood descriptors is important in determining the properties and class of the territory, as well as the spectral properties of the earth.

Morphometric parameters as an informative invariant descriptor of the territory. The determination of numerical parameters and properties of the relief can provide important invariant information about the analyzed territory. Authentic morphometric parameters are the slope and exposure of slopes. In practice, other parameters are calculated: bogging, density of girdering and hydrographic dissection, depth of erosion and other. To calculate these parameters, a height map is used, a rectangular matrix, each element of which contains a numerical value of the height of the Earth's point compared to it. Isolation of dynamic boundaries of geophysical areas. The boundaries of relief forms, types of soils, vegetation massifs and other natural and territorial components often correlate, although at the same time these relationships are complicated by the nature of the anthropogenic impact on the geosystems. It is of natural interest to analyze the threshold change in the brightness of the Earth's remote sensing data bordering on each other, since sharp fluctuations of this parameter very often appear on the boundaries of geosystems, in places where the reflectivity of the surface and illumination change. Approbation of the dynamic borders allocation algorithm based on this position showed that in the initial stage of the algorithm the image needs to be preprocessed: image smoothing is useful in combating noise, and it must be used to smooth undesirable differences between the brightness values of neighboring pixels.

2) The unit for assessing the geophysical diversity of landscapes by the method of calculating entropy and parameters of brightness variation is based on the fact that the informative parameter characterizing the properties of a territorial site is a measure of the diversity of its constituent components. At the level of remote sensing data of the Earth, the analysis of this parameter reduces to calculating the degree of diversity of pixel images in several spectral ranges. As a metric for the diversity of pixels belonging to a particular territory, it is advisable to select the information entropy, which is defined as a logarithmic function. An analysis of the inhomogeneity of the vicinity of the geophysical surface and changes in the spectral brightness of the objects of the vicinity indicates that the geophysical diversity at the local level depends on the features of the lithogenic base and the type of anthropogenic impact. 
3) The geophysical shell analysis unit through calculation of the neighborhood descriptors. Under the neighborhood of an elementary landscape area is meant the territory located within a certain radius from it. Analysis of color properties is also important in the characterization of spatial objects. A comprehensive account of the neighborhood descriptors can be determined by compiling the Fisher vector. Approbation of the methodology for the classification of geophysical objects on test ranges showed the distribution of the final classification accuracy in the range from 81 to $89 \%$ (without regard to the neighborhood), which, when taking into account the descriptors of the neighborhood, increases to $97 \%$. It is also revealed that an excessive increase in the radius of the considered neighborhood often leads to a regular decrease in the classification accuracy.

4) The ensemble-analysis unit for remote sensing data for the monitoring of the state of lands and forecasting of natural natural processes was implemented due to the fact that the analysis of the current situation in the sphere of pattern recognition showed the prospect of setting experiments to improve the accuracy of interpretation of multizone space images based on the Ensemble Learning concept. The key structural elements of ensemble-systems are: a set of monoclassifiers, formed from separate algorithmic blocks of controlled classification; classifiers can have as one nature, and completely different; metaclassifier - a component that analyzes the result of classification provided by monoclassifiers and takes the final decision about the belonging of an object to a class.

The use of ensemble-systems allows to perform automated analysis of large amounts of remote sensing data quickly for the purpose of thematic mapping of land-use systems and analysis of the development of emergencies and natural processes. Comparative analysis of the performance of individual mono-classifiers and ensemble-system allowed to draw the following conclusions: the ensemble-system in comparison with monomodels in each case showed a better or close to it result; the efficiency of the ensemble-system calculated in practice considerably exceeds the worst of the efficiencies of individual monoclassifiers, thus avoiding gross classification errors.

\section{The discussion of the results}

The application of the system of methods described in the previous section made it possible to carry out a geodiagnostic of lithohydrogene systems of the Republic of Mordovia with a view to predicting the development of exogeodynamic processes. To calibrate the learning process of intelligent automated classifiers, a test polygon system was used: «Inerka»valley of the river Sura (geographical coordinates of the central part of the landfill: $54 \circ 03^{\prime}$ $\mathrm{N}, 45 \circ 53^{\prime} \mathrm{E}$ ) - technique of estimation of geophysical diversity method of calculating the entropy spectral luminances was tested; «Cheberchinka» - forest-steppe erosiondenudation plain $\left(54 \circ 25^{\prime} \mathrm{N}, 46 \circ 18^{\prime}\right.$ E» - the technique of geophysical detection of increased diversity intervals by analyzing changes in the brightness of the spectral characteristics areas, based on the computation of finite differences and image gradients

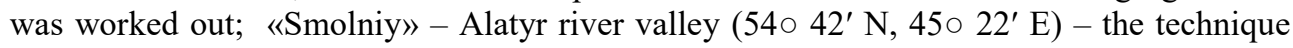
for delineating of the boundaries of geophysical sections was approved; it is based on the analysis of the spectral characteristics of neighboring geophysical sections and the algorithm for determining the boundary points.

The conducted experiments also confirmed that the use of ensemble systems for the analysis of remote sensing data provides several advantages: it allows to reduce errors and improve the accuracy of individual classifiers by combining them into the system; reduce the impact of the error resulting from the formation of test and training samples, due to ensemble-data analysis by a system of classifiers trained on independent data groups.

The ensemble-systems allow to achieve the solution of the task of parameterizing the classifier by sharing models of one class with different parameters. In the framework of the 
classification of the geophysical surface of the test polygon of "Inerka", the developed [1] ensemble system showed the best result in comparison with individual classificative models (8.02\% more accurate than the result shown by the decision tree - the best model from monoclassifiers) and ensemble systems of another architecture by $3.13 \%$ more accurate than the result of the ensemble, working on the basis of a simple vote and showing the second result).

The use of ensemble systems for decoding the materials of space imagery of the test polygon "Inerka" made it possible to assess the stability of geocomplexes of the territory for the purposes of construction, formation of recreational zones and accumulation of products of technogenesis (figure 2). Classification made it possible to separate aboriginal watersheds and sink and hollow complexes, sink and hollow complexes, and medium-level floodplains covered with broad-leaved forest. Studies have shown that the diversity of the natural and territorial complexes of the Lake Inerka and, in general, their weak resistance to anthropogenic impact should anticipate special circumspection when planning and locating economic and cultural objects.

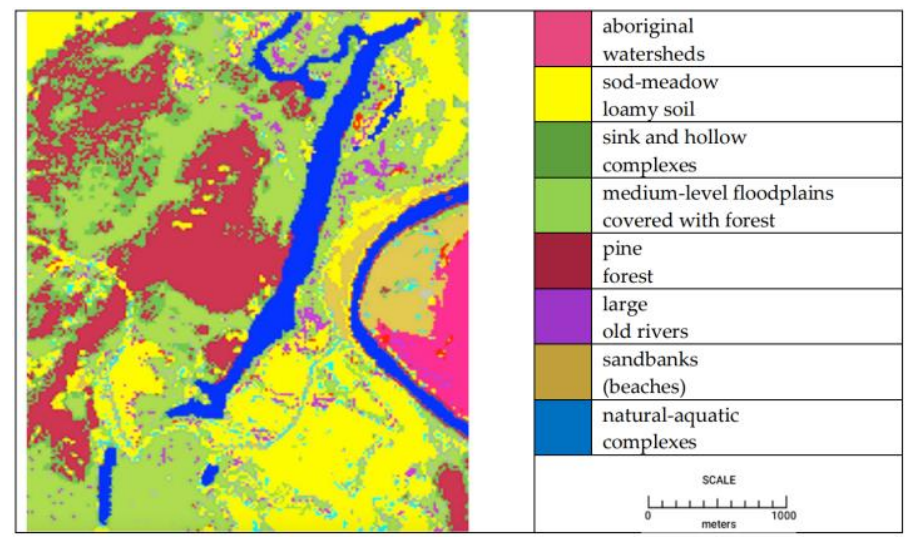

Fig. 2. The result of classification of the problem site of the Inerka test polygon.

The developed technologies made it possible to map lithohydrogene systems with the construction of a synthetic geoecological map (figure 3). When mapping the state and predicting the development of exogeodynamic processes, an important task is to determine the direction and intensity of groundwater movement that determine the formation of the morphological structure of landscapes. Taking these features into account, lithohydrogene geosystems are distinguished in the vertical structure of the lithogenic base of landscapes:

- groundwater filtration zones (zone A) - soil waters, perchage, capillary fringe waters, ground flows and parts thereof;

- zones of filtration of flowing non-pressure-subnapor interstate waters of interfluve spaces (zone B) - flows of stratigraphic-genetic water-conducting horizons and their parts, relatively waterproof layers, a system for locating water displays and a hydrographic network of different orders;

- filtration zones of hydrogeological structures of hydrodynamic zoning (zone B) reservoir aquifers of regional distribution, which are constituent parts of artesian basins in which the main reserves of fresh groundwater are concentrated; hydrodynamic parts: areas of nutrition, creation of heads, partial unloading.

The structure of lithohydrogene systems of the landscape envelope reflects spatial interrelations and interrelationships of groundwater flows in filtration areas; it depends on the properties of the aquifers, their quantity and interaction, the positions of the drained river valleys that control the boundaries of water flows. 


\subsection{Lithogidrogenic geosystems of the forest-steppe of erosion-denudation plain-planar-tiered Privolzhskaya Upland}

Ostankovo-watersheds with absolute elevations above $240 \mathrm{~m}$ above sea level (maximum height up to $334 \mathrm{~m}$ ). The western and north-western slopes are represented by a clear ledge with a height of $60-80 \mathrm{~m}$ and a steepness of $10-15^{\circ}$, in some places up to $40^{\circ}$. The southeastern slope is gently sloping, is topped by the numerous left tributaries of the Sura River. The watershed is flat and flat-convex. The geological cross section of lithohydrogene systems is composed of siliceous-carbonate rock-flocks and marls, with interlayers (up to $0.4 \mathrm{~m}$ ) of diatomites, trefoils and clays, and the highest (above $+300 \mathrm{~m}$ ) isolated sections of the watershed of the Alatyr and Sura rivers are sandstones with interlayers (up to $5 \mathrm{~m}$ ) of sand. The total thickness of sediments up to $110 \mathrm{~m}$. The water content is uneven and depends on the geological-lithological differences. Individual springs in the headwaters of streams and rivers have a production rate of about $31 / \mathrm{s}$. The waters are characterized by softness and low mineralization, the total hardness is $3.6 \mathrm{mmol} / \mathrm{dm} 3$, the dry residue is 330 $\mathrm{mg} / \mathrm{dm} 3$. The lower water-bearing of the aquifer is the clayey stratum of the upper cretaceous deposits, the top sometimes is the low-power loamy eluvial-deluvial sediments.

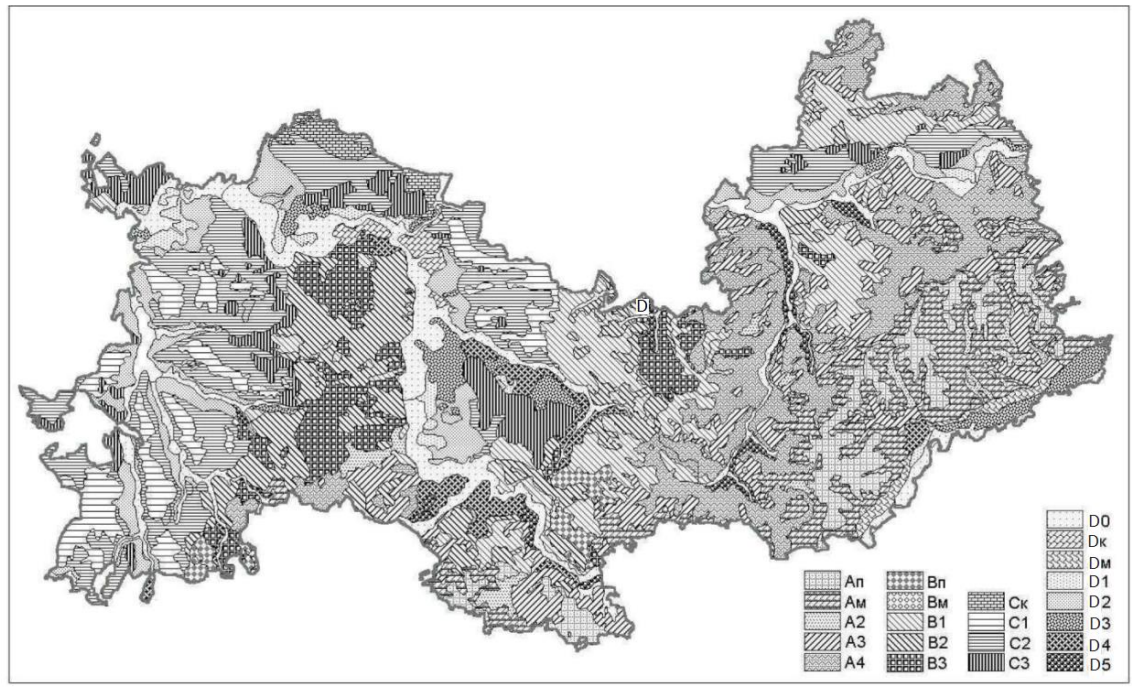

Fig. 3. Map of lithohydrogene geosystems (legend is in the text).

Alp - sublime remnant-watershed arrays stacked siliceous-calcareous rocks (flasks, marl, diatomite with interlayers and lenses of sand and clay) - feeding area litogidrogennyh zone A systems; the presence of local water-resistant interlayers in the Paleogene stratum in combination with a high degree of erosion dissection creates conditions for active discharge of water at the expense of the spring runoff; lithohydrogene systems corresponds to a single-layered region of filtration of open flow drainage streams with a pronounced spring flow, hydraulic communication with the waters of zone B is characteristic;

A1 - near-water-divided spaces formed under the influence of lithohydrogene systems of upper cretaceous aquifers, - feeding area; flow into the underlying aquifers; the presence of local waterproof interlayers in the sole of Upper Cretaceous sediments in combination with a high degree of erosion dissociation causes an active discharge of water; The geocomplex corresponds to the one-plate filtration area of the open flow drainage streams with pronounced spring water flow, weak hydraulic connection with the waters of zone B; 
A2 - wavy, gently sloping surfaces of watershed spaces, composed of eluvium of terrigenous rocks - feeding area; a high degree of erosion dismemberment creates the prerequisites for active discharge of water into ravines and girder systems;

A3 - undulating surfaces of the middle sections of the slopes, composed of eluvialdeluvial deposits of terrigenous rocks; a high degree of erosional partitioning causes an active discharge of water from the spring runoff; geosystems corresponds to a singlelayered filtration area for pro-current flows of open drainage with pronounced spring runoff, lack of hydraulic connection with the waters of zone B; zona A has sporadic distribution;

A4 - wavy surfaces of the near-bottom slopes, composed of the deluvium of terrigenous rocks - food is provided by the flow of water from adjacent aquifers, i.e. Ascending filtration and lateral underground inflow; Discharge of gravity water through lateral outflow.

\subsection{Litho-hydrogenic geosystems of the forest-steppe of the secondary morainic plains of the Privolzhskaya Upland's high-altitude slope are descending to the northwest}

The absolute level of up to $272 \mathrm{~m}$, predominate basin divide $230-250 \mathrm{~m}$ in height. The upper part near-water-divided slopes strongly indented ravine systems and has indicative scalloped shape. The main rivers that cut through the plains are Nuia, Insar and Rudnia-the right tributaries of the river. Alatyr, along with its numerous tributaries, form the Middle Russian type of the river network pattern. In southern Mordovia, the major rivers of the region originate: Sivin, Rudnya, Insar and their numerous tributaries. Upper rivers have the form of slotted beams steep slopes and ravines to 10-16 m in height and, on otdelnyh portions 25-30 m. Valley tributaries of the rivers Nuya, Insar, Rudnya in general have sublatitude direction. In parallel, they have their main water divisions of the second order, due to which the drawings of watersheds have the form of a grid. The river valleys are asymmetric, with steep slopes of southern and gentle slopes of northern exposure.

Litogidrogennye systems form: 1) the aquifer (locally weak-aquifer) albian terrigenious horizon timed to the fine- and coarse-grained clayey sands; depth of occurrence of groundwater up to $21.7 \mathrm{~m}$ from the earth's surface; sources usually have a small and unstable flow rate; sub-surface water soft, weakly mineralized, hydrocarbonate sodium; the main source of their food are atmospheric precipitation; 2) the low-water (aquiferous) Aptian terrigenous horizon has a limited distribution; they are enclosed in sandy clays and clayey sands and cover at various depths $(3,7-45,0 \mathrm{~m}$ from the surface); the discharge of the aquifer is small; the water of springs usually weakly percolates; 3 ) the water-bearing Barrarian terrigenous horizon is formed in sandy places; depth of occurrence of water varies from 8 to $116.3 \mathrm{~m}$; a thick layer of dense hauterivian clays; sources have debit 0,151 / s; water-sodium hydrocarbonate calcium mineralization $0.345 \mathrm{~g} / \mathrm{dm} 3$, is supplied by the infiltration of atmospheric precipitation, nutrition coincide with the regions close to the surface of occurrence Barremian rocks.

B1 - wavy and gently sloping surfaces of watershed spaces, composed of glacial deposits; area of primary feeding of water streams of zone B; high degree of erosion dismemberment creates the prerequisites for active water discharge due to spring runoff; geosystems correspond to a two-layer area of filtration of closed surface drainage flows of zone $\mathrm{B}$; the connection of the waters of zone B with the streams of zone B is nonobstructive.

B2 - wavy surfaces of the middle sections of the slopes, composed of moraine and deluvial loams - active discharge of water from the spring runoff; area of transit and discharge of groundwater flows in zone B. 
B3 - undulating surfaces of the near-bottom slopes, composed of deluvial loams - food is provided by the flow of water from adjacent aquifers, i.e. ascending filtration and lateral underground inflow; discharge of gravitational waters by means of lateral outflow; area of discharge of groundwater flows in zone B.

\subsection{Lithogidrogenous geosystems of coniferous and mixed forests of water- glacial and ancient alluvial plains of the marginal part of the layer-tiered Privolzhskaya Upland and the Oka-Don low-land}

It is occupy the central part of the Vad river basin, extend along the right bank of the Moksha and stretch along the left bank of the Alatyr and Sura narrow strips. A characteristic feature of fluvioglacial plains is gently wavy smooth surfaces with hilly-ridge dune morphosculptures. The main watersheds are located predominantly at absolute altitudes of 180-220 m. The watershed slopes are shallow, the aboriginal sides of the valleys are cut by beams and ravines. The rivers flow in wide valleys with terraced terraces on slopes with a developed longitudinal profile of equilibrium. The only exception is the part of the valley of the river Sivin at the intersection of the Sivin's structure, where carbonaceous limestones emerge on the earth's surface. The valleys of the rivers attract a lot of beams with gently sloping, sloped terrains, which are complicated by landslides.

Lithohydrogene systems are determined by the distribution of heterogenous sands, located above and below the moraine accumulations. The total thickness of alluvialfluvioglacial sediments is from 0.3 to $12.5 \mathrm{~m}$. The watered part of the sands, opened by the wells, has a capacity of up to $4.5 \mathrm{~m}$, in the wells the thickness of the watered rocks reaches $7.0 \mathrm{~m}$. The depth of the aquifer lies and varies from 0.1 to $6 \mathrm{~m}$. On the greater part of the area of its distribution, it lies first from the surface and is free-flowing with a free surface of groundwater. The horizon flow is always directed towards the river valleys and deep ravines. In the marginal parts of its distribution, underlying deposits are aboriginal. The water availability of the horizon is weak, the flow rate of the springs is $0.01-0.21 / \mathrm{s}$, less often - up to $0.551 / \mathrm{s}$. The coefficient of sand filtration is $0,45 \mathrm{~m} /$ day, rarely reaches 0,9 2,3 m / day. According to the chemical composition of the water horizon, hydrocarbonate calcium, in single cases, sulphate sodium, fresh, the great mineral varies from 0.48 to $0.65 \mathrm{~g}$ $/ \mathrm{dm}^{3}$. The water is soft and moderately hard, with a total hardness of $0.76-5.75 \mathrm{mmol} /$ $\mathrm{dm}^{3}$. The concentration of hydrogen ions varies from 5.9 to 8.4. Oxidation in oxygen is 2.2 - $2.48 \mathrm{mg} / \mathrm{dm}^{3}$. The water-bearing horizon is fed by infiltration of atmospheric precipitation, in some areas - by water flowing from the bedrock. Unloading is carried out by overflowing through the "lithologic windows" into the water-bearing horizons, which are arranged hypsometrically below. In low parts of the terrain, when lying close to the surface, groundwater feeds swamps.

The lithological composition of the aeration zone consists mainly of fluvioglacial sands, morainic loams, less common are lower pleistocene-pliocene and miocene sands, eluvialdeluvial and lacustrine-glacial sugulines, eolian sands and sandy loams, underlain by terrigenous sandy-clayey lower cretaceous and jurassic sediments, carbonate rocks of the permian and carboniferous ages;

C1 - geosystems of low-wavy interfluvial spaces, composed of a layer of overmorbed fluvioglacial deposits lying on the Dnepr's moraine with sod-medium- and strongly podzolic soils-the feeding area; discharge of groundwater occurs mainly in the sub-river streams of the river valleys or they seep in the bottoms of the catch basins of the beams; type of geosystems corresponds to a one-plate filtration area of open streams belonging to zone B.

C2 - geosystems of low-winded interfluvial spaces, composed of fluvioglacial deposits on morainic and aboriginal loams and clays - the feeding area; discharge of groundwater 
occurs mainly in sub-river streams of river valleys or seeps in the bottoms of the catch basins of beams; single-layer filter region of open flows belonging to zone B.

C3 - flat, rarely slightly volatile interfacial spaces, composed of fluvioglacial deposits on morainic and indigenous loams and clays - the feeding area; unloading of groundwater occurs mainly in sub-river streams of river valleys or they seep in the bottoms of the catch basins of beams; single-layer filtration area of open streams belonging to zone B.

D - lithogidrogenic geosystems of valleys of large and medium rivers. Unloading of aquifers is carried out in the form of lateral underground outflow and drainage into riverbeds.

\subsection{General regularities of the functioning of lithohydrogene geosystems}

The largest values of the aeration zone power are characteristic for the residual-watershed massifs of erosion-denudation plains of the Volga Upland, composed of flocks, marls, trembles, and sands of the Paleogene. The general regularity of the depth of occurrence of groundwater is its gradual decrease from near-water-divided to near-valley nature territorial complexes of the secondary morainic and water-glacial plains.. The main groundwater feeding areas are confined, in the main, to the following genera of geosystems A1n, A1m, A2, B1, C1, C2, C3, C3. In geosystems B3, A4, Am and valley landscapes, the supply of groundwater is mainly due to the upward filtration and lateral underground inflow.

Unloading of groundwater, as well as feeding conditions, depend on the structures of lithohydrogene geosystems. The flow to the lower aquifers is characteristic of the genera of the geosystems A1p and A1m. The presence of local waterproof interlayers in the sediments of these types of geosystems, combined with high erosion dissection, creates the possibility of unloading at the expense of spring runoff. In the genera of geosystems A2, A3, B1, B2, discharge of water is carried out in negative forms of relief. For geosystems A4, A4, B3, which is characterized by a weak erosion dissection, a lateral underground outflow is common. Discharge of water-bearing horizons of valley landscapes is carried out in the form of lateral underground outflow and drainage into riverbeds. In the conditions of the subsidence of quaternary sediments, fissured carbonate rocks, lack of water retaining, and in the presence of a non-pressure regime of the underlying aquifer, water infiltration occurs. The greatest density of outcrops of groundwater are the types of geosystems A1p, A1m, A2, A3, B1, B2.

The boundary between the waters of zones A and B is usually conformed with the first regional water supply. Under such conditions, a well-defined horizon of groundwater is formed, as a rule. The connection of the waters of zone A with artesian ones is absent or strongly delayed. The boundary is indicated by local bases of erosion. This type of lower boundary is characteristic for lithogidrogenic geosystems A2, A3, A4, B1, B2, B3, B1, B2, etc.

The second type of boundary between zones A and B is similar to the first one. Its distinctive feature is the presence of a powerful aeration zone and a significant deadhorizon capacity. Hydraulic communication of soil and groundwater is completely absent. The lower boundary is based on a lithological feature - thicker than the significant weakening of the fracture of rocks. Groundwater is mined. The connection of the waters of zone A with artesian is difficult. This type of boundary is characteristic of lithohydrogen geosystems of $\mathrm{Al}$ erosion-denudational dales.

The third type of boundary of zones A and B is typical for river valleys. It coincides with the roof of the waterproof horizon of bedrock, overlapped on top of the thickness of water-permeable rocks. A well-formed and shallow-lying horizon of groundwater forms. In geocomplexes, there is a constant or periodic hydrological connection between soil and groundwater. A distinctive feature is that in the "hydrogeological windows" consisting of 
water-permeable rocks there is a constant hydraulic connection between landscape and artesian waters. This type of lower boundary is characteristic of lithohydrogen geosystems DOt. The fourth type of the boundary is isolated in lithogidrogenic geosystems in the formation of which limestones and dolomites of the carbon participate (Ck, Dk). Fractured limestones and dolomites can not serve as a water-resistant horizon, so mixing of waters of zones A, B and B occurs.

Underground waters wash out, leach, soften rocks, create additional loads. The filtration of water flows from the feeding area to the unloading zones, with a certain degree of conventionality, is divided into three zones: the accumulation zone, the transportation zone (transit), the unloading zone. Each of the selected zones corresponds to a characteristic landscape pattern.

\subsection{Regularities in the development of exogeodynamic processes}

Features of the structure of lithohydrogene geosystems determine the development of landslide, karst, erosion, suffosion and eolian processes.

\subsection{Landslide formation}

The situation on the northwestern slope of the Volga Upland, the westward transition to the Oka-Don lowland, determines the general patterns of the spread of landslides. A significant part of them is located in the altitude range from 120 to $250 \mathrm{~m}$, with a maximum concentration at absolute elevations of $141-210 \mathrm{~m}$. These elevation marks are the largest landslide relief forms. Least-water dividing massifs (above $250 \mathrm{~m}$ ) of the axial part of the Volga Upland are the least subject to landslide formation, where landslides are encountered sporadically. It should be noted that the distribution of springs has a similar regularity. The high correlation between the development of landslide processes can be traced to the structure of lithohydrogene systems. It is important to note the general pattern of spreading landslide processes - they gravitate toward the slopes of south-western, southern and southeastern exposures, which is probably connected with the peculiarities of tectonic structures. Landslides-blocks, landslides-mudflows and landslides-failures, viscoplastic landslips, landslides of shear-flow (combined mechanism), landslides of shear are distinguished.

\subsection{Karst processes}

It is develop lithohydrogene systems of the Moksha-Alatyr interfluve, in the region of the outlet to the daily surface of limestone and dolomite of carboniferous and permian ages. The following karst forms of relief are distinguished according to morphology peculiarities: 1) basins of karst origin, which are cup-shaped depressions, sometimes filled with water, as, for example, Lake Endovishche in Temnikovsky District; 2) cup-shaped funnels are characterized in terms of a large variety of shapes from round to irregular; a complex wrong form is due to the merging of several funnels into one and the presence of gravitational and erosion processes developing along the slopes; steepness of slopes from 15 to $30^{\circ} ; 3$ ) saucer-shaped funnels (depressions) in plan have an oval or irregular shape; the slopes are sloping with a slightly inclined profile, the bottom is wide and flat. Carving rocks limestones and dolomites of the upper carboniferous and asselian stage of the lower permian in the described territory lie mainly at shallow depths (on average 15-20 m). Many areas of superficial karst manifestations and individual karst craters are noted, but the valleys predominate. The density of the funnels does not exceed 15 pieces per $1 \mathrm{~km}^{2}$. 


\subsection{Chalky karst}

It is a subtype of carbonate karst, develops in chalk and chalk-like rocks of upper cretaceous age. It is distributed only in the southeastern part of Mordovia on the Insara-Sura interfluve. Destructive consequences from karst processes in the territory of Mordovia were not noted, however, the geological structure favorable to its potential development (the presence of mature sequences of carbonate formation) of a significant part of the territory determined the attribution of this process to the category of dangerous ones.

\subsection{Sheet and linear erosion}

The greatest variety of manifestations is characterized by erosion processes. The initial forms of erosion are reflected in the tone or color of soils and vegetation. The eroded erosion is deciphered according to a linearly extended pattern of the geo-systems of the gullies and ravines. The intensity of the process can be assessed qualitatively by the density of the erosion network, the emergence of new erosion forms, the change in the growth of previously formed erosional forms of relief (using snapshots of repeated surveys). As a rule, the more washed soil becomes light-coloured. Its homogeneous structure becomes spotty. In areas with the distribution of structural and denudational relief on sandyargillaceous rocks erosion-landslide circuses are often formed. The main role of these formation is played by landslide processes arising as a result of abrasion. Erosion-landslide circuses are well deciphered in their morphological features, however their relative growth is determined by geobotanical data. You can distinguish circuses of two stages: "young" and "old".

\section{Conclusions}

1. The landscape indication, based on the automated analysis of remote sensing data, is one of the key methods of research and mapping of lithohydrogene geosystems, which are part of the ACAS. The main sources of information for studying the development of exogeodynamic processes are GIS, in which information on the manifestations of landslide, erosion, suffosion, karst processes occupies an important place. The process of generating synthetic maps of lithohydrogene geosystems is expedient to be based on interpretation of multi-zonal space images, in the process of which information resources of geospatial data were taken into account.

2. Medium-scale synthetic geoecological mapping, performed for the purpose of geodiagnostics of lithohydrogene systems for forecasting exogeodynamic processes, forms a hierarchical system of taxa, including: classes and subclasses, groups and subgroups, types and subtypes, genera and subgenus of geosystems, and types of geosystems. Accordingly, the automated construction of synthetic maps of lithohydrogene geosystems is expedient to be carried out using a system approach.

3. For effective detection of types of lithohydrogene systems, a set of methods has been developed, which includes the following modules: allocation of dynamic and invariant descriptors of the territory; assessment of geophysical diversity of landscapes; analysis of the geophysical shell through the calculation of the descriptors of the neighborhood; ensemble-analysis of remote sensing data for monitoring the state of lands and forecasting natural processes. Each of them is informative in distinguishing certain characteristic direct or indirect features of the studied area, but in combination they are capable of giving the most effective and accurate result of a landscape indication.

4. The approbation of the methodology in the classification of geophysical objects on test polygons showed the distribution of the final classification accuracy in the range from 
81 to $89 \%$ (without regard to the neighborhood), which, when taking into account the descriptors of the neighborhood, increases to $97 \%$. It is also revealed that an excessive increase in the radius of the considered neighborhood often leads to a regular decrease in the classification accuracy.

The conducted experiments confirmed the effectiveness of the use of ensemble systems: in the classification of the geophysical surface of the test place "Inerka", the tested ensemble system showed the best result in comparison with individual classification models (8.02\% more accurate than the result shown by the decision tree - the best model from monoclassifiers) and ensemble systems of other architecture (3.13\% more accurate than the ensemble result, operating on the basis of simple voting and showing the second result). Comparative analysis of the performance of individual mono-classifiers and ensemblesystem allowed to draw the following conclusions: the ensemble-system in comparison with monomodels in each case showed a better or close to its result.

The efficiency of the ensemble-system calculated in practice considerably exceeds the worst of the efficiencies of individual monoclassifiers, thus avoiding gross classification errors.

5. The system of methods for detecting the types of landscapes allowed to conduct geodiagnostics of lithohydrogene systems of the Republic of Mordovia with the aim of predicting the development of exogeodynamic processes. In the vertical structure of the lithogenic base of landscapes, the following lithohydrogene geosystems are distinguished: groundwater filtration zones (zone A); zones of filtration of flowing non-pressure-subnaptic interplastic waters of interfluve spaces (zone B); zone of filtration of hydrogeological structures of reservoir hydrogeodynamic zonation (zone B). The structure of lithohydrogene systems of the landscape envelope reflects the spatial relationships and interrelationships of groundwater flows of filtration areas and depends on the properties of the aquifers and the position of the draining river valleys.

6. The complex application of automated remote sensing data acquisition tools and analytical analysis of information concentrated in the regional GIS "Mordovia" made it possible to give a detailed description of the erosion-denudation plains of the Privolzhskaya Upland and the secondary morainic plains of the layered high-altitude Privolzhskaya Upland to lithohydrogen geosystems of the forest-steppe; coniferous and mixed forests of water-glacial and ancient alluvial plains of the marginal part of the layer-tiered Privolzhskaya Upland and the Oka-Don lowland placer.

7. The conducted study made it possible to single out general patterns of functioning of lithohydrogene geosystems. The largest values of the aeration zone power are characteristic for the residual-watershed massifs of erosion-denudation plains of the Volga Upland, composed of flocks, marls, trembles, and sands of the Paleogene. The general regularity of the depth of occurrence of groundwater is its gradual decrease from near-water-divide to near-valley nature territorial complexes of the secondary morainic and water-glacial plains. It was revealed that discharge of groundwater, as well as food conditions, depend on the structures of lithohydrogene geosystems.

Discharge of water-bearing horizons of valley landscapes is carried out in the form of lateral underground outflow and drainage into riverbeds. In the conditions of the subsidence of Quaternary sediments, fissured carbonate rocks, lack of water retaining, and in the presence of a non-pressure regime of the underlying aquifer, water infiltration occurs. The geoecological role of lithohydrogene systems is significant.

Underground waters wash out, leach, soften rocks, create additional loads. To assess the stability of the lithogenous basis and predict the development of destructive geoecological processes, it is promising to attract information about the latest tectonic structures. 


\section{References}

1. S. Yamashkin, M. Radovanovic, A. Yamashkin, D. Vukovic, Journal of Hydroinformatics 20(4), 753-765 (2018) doi: 10.2166/hydro.2018.076

2. S. Yamashkin, M. Radovanovic, A. Yamashkin, D. Vukovic, Data 2(3) (2018) doi: 10.3390/data3020018

3. C. Woodcock, A. Strahler, J. Smith, Remote Sens. Environ 20, 121-139 (1984)

4. D. Landgrebe, Signal Theory Methods in Multispectral Remote Sensing (Wiley, New York, 2003)

5. R. Schowengerdt, Remote Sensing: Models and Methods for Image Processing (Academic Press, New York, 2007)

6. L. Breiman, Mach. Learn 24, 123-140 (1996)

7. D. Rumelhart, G. Hinton, J. McClelland, A General Framework for Parallel Distributed Processing (MIT Press, Cambridge, 1999)

8. V. Vapnik, The Nature of Statistical Learning Theory (Springer, Berlin/Heidelberg, 1995)

9. R. Polikar, IEEE Circuits Syst. Mag 6, 21-45 (2006) 